\title{
Neuromodulation of the Cervical Spinal Cord in the Treatment of Chronic Intractable Neck and Upper Extremity Pain: A Case Series and Review of the Literature
}

Ricardo Vallejo ${ }^{1,2}, \mathrm{MD}, \mathrm{PhD}$, Jeffery Kramer ${ }^{1,2,3}, \mathrm{PhD}$, and Ramsin Benyamin ${ }^{1,2,3}, \mathrm{MD}$

From: ${ }^{1}$ Millennium Pain Center, 2lllinois State University, Bloomington, IL, ${ }^{3}$ University of Illinois, Urbana-Champaign, IL Dr. Vallejo ${ }^{1}$ is Director of Research, Staff Pain Medicine, Millennium Pain Center, and Adjunct Professor of Biology, llinois State University, Bloomington, IL. Dr. Kramer ${ }^{2}$ is with the Department of Biology, Illinois State University and the College of Medicine at Peoria, Department of Cancer Biology and Pharmacology,

Peoria, IL. Dr. Benyamin ${ }^{3}$ is President, Millennium Pain Center,

Bloomington, IL, and Clinical Instructor, Department of Surgery, College of Medicine, University of Illinois, Urbana-Champaign, IL. Address Correspondence: Ricardo Vallejo, MD, PhD Millennium Pain Center 1015 S. Mercer Ave. Bloomington, IL 61701

E-mail: vallejo@

millenniumpaincenter.com Disclaimer: There was no external funding in the preparation of this manuscript.

Conflict of Interest: None Manuscript received:10/25/2006 Revisions accepted: 12/07/2006 Accepted for Publication: $1 / 29 / 2007$

Free Full manuscript: www.painphysicianjournal.com
Electrical spinal neuromodulation in the form of spinal cord stimulation is currently used for treating chronic painful conditions such as complex regional pain syndrome, diabetic neuropathy, postherpetic neuralgia, peripheral ischemia, low back pain, and other conditions refractory to more conservative treatments. To date, there are very few published reports documenting the use of spinal cord stimulation in the treatment of head/neck and upper limb pain. This paper reports a case series of 5 consecutive patients outlining the use of spinal cord stimulation to treat upper extremity pain. All subjects had previously undergone cervical fusion surgery to treat chronic neck and upper limb pain. Patients were referred following failure of the surgery to manage their painful conditions. Spinal cord stimulators were placed in the cervical epidural space through a thoracic needle placement. Stimulation parameters were adjusted to capture as much of the painful area(s) as possible. In total, 4 out of 5 patients moved to implantation. In all cases, patients reported significant (70-90\%) reductions in pain, including axial neck pain and upper extremity pain. Interestingly, 2 patients with associated headache and lower extremity pain obtained relief after paresthesia-steering reportedly covered those areas. Moreover, 2 patients reported that cervical spinal cord stimulation significantly improved axial low back pain. Patients continue to report excellent pain relief up to 9 months following implantation. This case series documents the successful treatment of neck and upper extremity pain following unsuccessful cervical spine fusion surgery. Given this initial success, prospective, controlled studies are warranted to more adequately assess the long term utility and cost effectiveness of electrical neuromodulation treatment of chronic neck and upper extremity pain.

Key words: spinal cord stimulator, cervical, neck pain, radicular pain, axial pain, headache, leg pain

Pain Physician 2007; 10:305-311 
S pinal neuromodulation for the management of chronic pain conditions exists in 2 basic forms: chemical neuromodulation or electrical neuromodulation. Spinal chemical neuromodulation is exemplified by the use of epidural injections or the intrathecal delivery of drugs (1-3), whereas electrical spinal neuromodulation is produced by the use of spinal cord stimulation (SCS) devices $(4,5)$. An increasing number of reviews on the use of this technology in the treatment of a variety of pain conditions have been written summarizing the short- and long-term effectiveness, purported mechanism(s) of action, and cost benefits (6-11). Despite the growing literature base documenting the use of SCS in the treatment of chronic pain conditions, to our knowledge, there have been very few reports detailing the use of spinal cord stimulation therapy to treat chronic pain following failed cervical spinal surgery (12).

One predominant indication for SCS is the relatively nebulous diagnosis of failed back surgery syndrome (FBSS) (8,13-17). In general, back surgery that does not adequately relieve pain in an individual is labeled as "failed." Reasons for the lack of success can be multifold including incorrect patient selection, poor technique, recurrent pathology, and a variety of other causes (18). Relatively recent randomized trials suggest that spinal cord stimulators provide an effective therapeutic option in the treatment of FBSS $(14,15,19)$. In a prospective, controlled study by North et al (19), patients were randomized to either a spinal cord stimulation group or a re-operation group. Either group could cross over to the other if the initial randomized treatment failed to adequately control pain. A greater percentage of the re-operation patients crossed over into the spinal cord stimulation group as opposed to SCS subjects crossing over into the re-operation group. Moreover, spinal cord stimulation offered a greater chance of successfully controlling pain as opposed to re-operation. This study suggests that spinal cord stimulation may more effectively control the pain of FBSS.

In contrast to the amount of study devoted to the efficacy and cost-effectiveness of SCSs in the treatment of low back pain, relatively little is published about the use of spinal cord stimulators in the treatment of neck and upper limb pain. In upper extremity pain most studies have focused on a variety of chronic pain conditions such as diabetic neuropathy (20-22), complex regional pain syndrome $(8,23,24)$, Raynaud's phenomenon (2527), painful peripheral vascular disorders (28-31), and pain resulting from brachial plexus avulsion (32), just to name a few. In particular, there is little published about the effectiveness of spinal cord stimulators in the treatment of neck (axial) and upper limb pain after neck surgery. In this paper we present a series of 5 consecutive cases where neck and/or upper limb pain were treated with cervical spinal electrical neuromodulation. In particular, we focused on patients that had a prior neck surgery without sufficient pain relief. Outcomes, complications, and recommendations are discussed.

\section{Case Series}

Five consecutive patients treated with spinal cord stimulators epidurally placed in the cervical spine region for the treatment of neck and/or upper limb pain were identified through chart review and included in the study. All patients had uncontrolled neck and/or upper extremity pain despite aggressive interventional procedures prior to being considered candidates for cervical spinal electrical neuromodulation. In all cases, radiological reports (including x-rays, MRIs, and CTs) were mostly unremarkable. No significant structural instability, stenosis, or cord impingement was noted. In most cases, slight cervical disc degeneration was noted at 1 or more levels with or without a slight disc bulge or very slight disc herniation. In no cases were pseudoarthrosis or myeloradiculopathy noted. Physical exams including a neuromuscular exam were normal with normal deep tendon reflexes, muscle strength, and gait stability.

Three out of 5 patients underwent diagnostic cervical facet joint injections prior to spinal cord stimulator trials in order to rule out sources of pain amenable to treatment with radiofrequency lesioning. Although 3 of the patients reported significant relief following diagnostic cervical facet medial branch blocks, subsequent radiofrequency denervation failed to achieve sustained reductions in pain. In all cases, patients had previously undergone anterior cervical fusion surgeries without successful reductions or adequate control of neck and/or upper limb pain. Based on history, physical examination as well as imaging, patients were not considered surgical candidates. Because we were unable to further rule out other sources of pain and, similar to FBSS, accounted the pain to an idiopathic, chronically intractable neck pain syndrome in which the pain following the so-called failed neck surgeries persisted for at least 3 months.

In both the trial phase and the implant phase (if warranted) patients were brought to the fluoroscopy/ surgery suite and placed in the prone position. One 
gram of intravenous cefazolin was given prophylactically and $1 \%$ lidocaine was administered for skin and subcutaneous anesthesia. Using a sterile technique and under direct fluoroscopic visualization, a \#14 epidural needle via a paramedian approach was used to identify the T3-4 epidural space by using the loss of resistance technique. Leads were typically advanced in the dorsal epidural space to the C2-4 level. Sensory stimulation and programming was completed to capture as much of the painful regions as possible. Trials lasted for between 5 and 7 days at which point patients rated pain relief on a 100 point numerical rating scale (percentage). If trials produced at least $50 \%$ pain relief then the option to move forward with the implantation phase was discussed.

\section{Results}

A total of 5 patients were trialed with circumferential style leads manufactured by Advanced Bionics (2 patients), Advanced Neuromodulation Systems (2 patients), or Medtronic (1 patient). Patient details are outlined in Table 1 . In most cases $(4 / 5 ; 80 \%)$ patients indicated significant pain relief ( $>50 \%$; mean $82.5 \% \pm$ $6 \%$, range $50 \%-90 \%)$. In 1 case the patient indicated that he did not obtain at least $50 \%$ pain relief, predominantly because of persistent complaints of pain over the spinous process at C7. This pain was not alleviated with local infiltration of local anesthetic and methylprednisolone (to rule out neuroma). Interestingly, this patient had a diagnosed C7 radiculopathy with a potential deafferentation syndrome. As a result

Table 1. Summary of patient information including pain locations, prior surgeries, pharmacotherapy, interventional procedures attempted, lead positions and outcomes. TENS = transcutaneous electrical nerve stimulation, CESI = cervical epidural steroid injection, $C F D B=$ cervical facet diagnostic blocks, CFRFL = cervical facet radiofrequency lesion.

\begin{tabular}{|c|c|c|c|c|c|c|c|c|c|}
\hline Patient & Age & Gender & $\begin{array}{l}\text { Prior } \\
\text { Surgeries }\end{array}$ & $\begin{array}{l}\text { Pain } \\
\text { Location(s) }\end{array}$ & Medications & $\begin{array}{l}\text { Attempted } \\
\text { Treatments }\end{array}$ & $\begin{array}{l}\text { Trial } \\
\text { Relief }\end{array}$ & $\begin{array}{l}\text { Trial / Implant } \\
\text { Lead Position }\end{array}$ & $\begin{array}{l}\text { Implant } \\
\text { Relief }\end{array}$ \\
\hline A & 39 & M & $\begin{array}{l}\text { C7-T1 } \\
\text { Foramenotomy } \\
\text { C7-T1 Fusion }\end{array}$ & $\begin{array}{l}\text { Neck, Left } \\
\text { Arm } \\
\text { (C3-C7 } \\
\text { Distribution) }\end{array}$ & $\begin{array}{l}\text { Opiates } \\
\text { NSAIDs }\end{array}$ & $\begin{array}{l}\text { Physical } \\
\text { Therapy } \\
\text { TENS } \\
\text { CESI } \\
\text { CFDB } \\
\text { CFRFL } \\
\end{array}$ & $\begin{array}{l}<50 \% \\
\text { Neck \& } \\
\text { Arm }\end{array}$ & $\begin{array}{l}\text { C3 } \\
\text { Dual 8-contact } \\
\text { Trial Leads }\end{array}$ & N/A \\
\hline B & 56 & M & $\begin{array}{l}\text { C6-7 } \\
\text { Discectomy } \\
\text { C6-7 Fusion }\end{array}$ & $\begin{array}{l}\text { Neck, Back, } \\
\text { Feet Headache } \\
\text { (C2-7 \& L4-S1 } \\
\text { Distribution) }\end{array}$ & Topromide & $\begin{array}{l}\text { Physical } \\
\text { Therapy } \\
\text { TENS } \\
\text { CFDB } \\
\text { CESI } \\
\text { CFRFL }\end{array}$ & $\begin{array}{l}70 \% \\
\text { Total Body }\end{array}$ & $\begin{array}{l}\text { C2-3 / C3 } \\
\text { Single 8-Contact } \\
\text { Lead }\end{array}$ & $\begin{array}{l}>90 \% \\
\text { in neck, } \\
\text { back, feet } \\
(9 \\
\text { months); } \\
\text { some } \\
\text { headache } \\
\text { relief }\end{array}$ \\
\hline $\mathrm{C}$ & 57 & M & C5-7 Fusion & $\begin{array}{l}\text { Neck, Bilateral } \\
\text { Shoulder, Feet } \\
\text { (C3-7 \& L2-S1 } \\
\text { Distribution) }\end{array}$ & Opiates & $\begin{array}{l}\text { Physical } \\
\text { Therapy } \\
\text { TENS } \\
\text { Acupuncture } \\
\text { CESI }\end{array}$ & $\begin{array}{l}80 \% \\
\text { Neck \& } \\
\text { Shoulder }\end{array}$ & $\begin{array}{l}\text { C3 / C3 } \\
\text { Single 8-Contact } \\
\text { Lead }\end{array}$ & $\begin{array}{l}70 \%(1 \\
\text { month) }\end{array}$ \\
\hline $\mathrm{D}$ & 72 & M & C5-7 Fusion & $\begin{array}{l}\text { Neck and } \\
\text { Bilateral } \\
\text { Shoulder and } \\
\text { Arm } \\
\text { (C4-C8 } \\
\text { \& L2-L5 } \\
\text { Distribution) }\end{array}$ & $\begin{array}{l}\text { Opiates } \\
\text { NSAIDs }\end{array}$ & $\begin{array}{l}\text { Physical } \\
\text { Therapy } \\
\text { CESI } \\
\text { Trigger Point } \\
\text { BoTox } \\
\text { Suprascapular } \\
\text { Block } \\
\text { CFDB } \\
\text { CFRFL }\end{array}$ & $\begin{array}{l}80 \% \\
>\text { Shoulder } \\
\& \text { Arm } \\
<\text { Neck }\end{array}$ & $\begin{array}{l}\text { C3 / C4 } \\
\text { Single 8-Contact } \\
\text { Lead }\end{array}$ & $\begin{array}{l}>50 \%(8 \\
\text { months) }\end{array}$ \\
\hline $\mathrm{E}$ & 44 & $\mathrm{~F}$ & C5-6 Fusion & $\begin{array}{l}\text { Neck, } \\
\text { Shoulder, } \\
\text { Right Arm, } \\
\text { Low Back } \\
\text { (C2-7 } \\
\text { Distribution) }\end{array}$ & $\begin{array}{l}\text { Opiates } \\
\text { Pregabalin } \\
\text { Muscle } \\
\text { Relaxants }\end{array}$ & $\begin{array}{l}\text { TENS } \\
\text { Physical } \\
\text { Therapy }\end{array}$ & $\begin{array}{l}100 \% \\
\text { Total Body }\end{array}$ & $\begin{array}{l}\mathrm{C} 2 / \mathrm{C} 3 \\
\text { Dual 8-Contact } \\
\text { Leads }\end{array}$ & $\begin{array}{l}>90 \% \text { (2 } \\
\text { months) }\end{array}$ \\
\hline
\end{tabular}




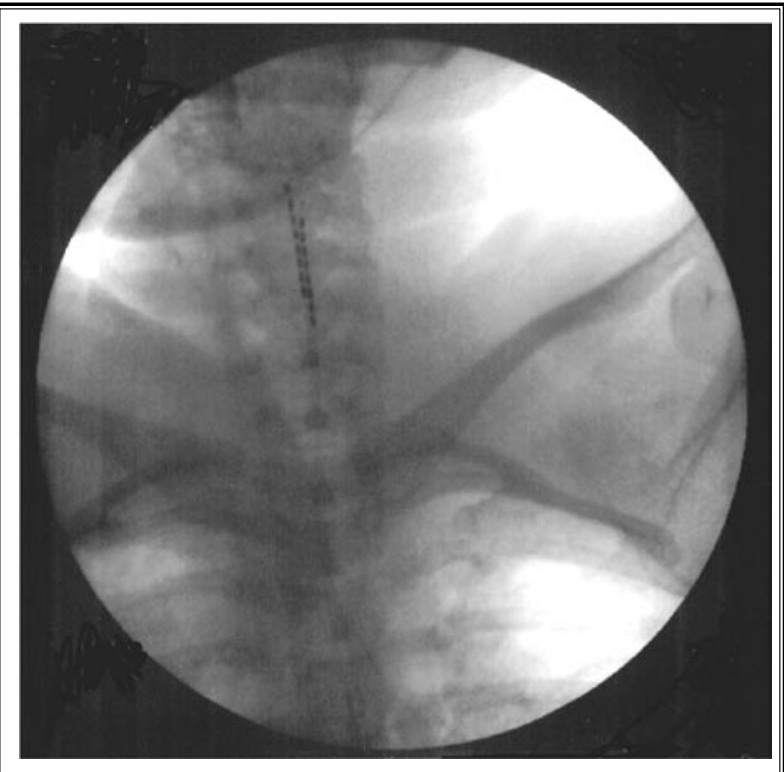

Fig. 1. Cervical placement of dual spinal cord stimulator leads. This patient obtained very good relief of elbow and hand pains. Interestingly, this patient could also feel paresthesia in the mandible.

of the poor relief obtained during the trial, the patient did not want to move on to the implant phase. Including the patient that had an unsuccessful trial, the mean trial pain relief was $75 \% \pm 8.9 \%$. In another case, the device failed following implantation and a revision had to be completed with a different lead type. The longest follow-up time recorded is 8 months with the patient still reporting $>50 \%$ relief. The range of follow-up is 1 month to 9 months with 4/4 patients reporting an average pain relief at approximately $70 \%$. It is unclear if there is any "creep" in pain levels, also termed "tolerance," over time as reported in other papers (33). However, 2 patients have reported high $(>90 \%)$ and moderately high $(>70 \%)$ levels of pain control at 6 months and longer. It is important to recognize that in 4 out of 5 patients, spinal cord stimulation was able to significantly alleviate not only upper extremity pain in the shoulders and arms but also in an axial distribution. Primarily this axial pain reduction was in the neck, however 2 patients reported axial relief (both $>50 \%$ ) in the low back with a spinal cord stimulator placed in the cervical region. Pain relief was, for the most part, similar between the axial and distal regions with the exception of 1 patient that found somewhat better relief in the upper extremities compared to the neck.
Most patients report paresthesia mapping along a C2-C3 dermatome pattern. In all cases, the neck and upper limbs (from the shoulder to the fingers) could be captured. In some cases, paresthesia was reported in the occipital region of the head and in another case in the mandible region, which is again consistent with a C2 dermatome sensory innervation (Fig. 1). In 3 cases patients reported head to toe paresthesias which were able to cover other more distal pain regions including low back, legs, and feet. Two patients reported the ability to drive the paresthesia supraoccipitally to the parietal region of the head. This coverage was able to help alleviate cervicogenic headache pain in tandem with upper and lower extremity pain. In no cases did we observe lead migration. In cases where optimal paresthesia coverage was lost, we could always recapture the painful regions by reprogramming.

\section{Discussion}

The use of spinal electrical neuromodulation as an advanced treatment to alleviate chronically intractable painful conditions is steadily increasing in both the number of patients being treated as well as an ever-expanding list of indications for which spinal cord stimulation is effective. One predominant use of spinal cord stimulators is in the treatment of FBSS $(8,16,19,34)$. In the current case series, we present 5 patients that underwent spinal cord stimulation following a so-called failed neck surgery. In all cases, anterior cervical spinal fusions failed to adequately control or alleviate pain in the neck and/or upper limbs. This condition is analogous to FBSS in the fact that a surgical procedure failed to control pain and there exists, basically, an idiopathic painful condition. Moreover, despite that $60 \%$ (3 out of 5 ) of the cases obtained relief after dual facet medial branch blocks, none of them responded to radiofrequency ablation. The reason for the lack of response to radiofrequency ablation following dual medial branch blocks is unclear. Previous papers have documented approximately 75-85\% dual block specificity $(35,36)$. The discrepancy could be partly explained by multiple false positive results. Recently, a preliminary report of a randomized, controlled trial by Manchikanti et al (37) demonstrated significant long-term pain relief following medial branch blocks without steroids ( $13.4 \pm 3.5$ weeks). This duration of pain relief is significantly longer than the local anesthetic duration of action and suggests that facet joint pain may have a neuropathic component (38). This latter point would help explain the lack of 
efficacy following radiofrequency ablation and yet the success of spinal cord stimulation therapy.

Since the epidural space in the cervical region is relatively narrow compared to the thoracic or lumbar regions, lead placement can be met with some resistance, especially when attempting to place 2 leads. Also, the second cervical vertebral level is currently about the highest the leads can be placed. Some benefit might be gained by capturing higher dermatomal levels although the placement of leads in this upper cervical region would be technically difficult given the anatomy of the epidural space and connectivity of the dura in the C2 spinal region. In all cases, generators were implanted in the hip/buttock region. Despite this relatively long distance from the lead tips to the implanted pulse generator, we observed no lead migration. It should be noted that all of the patients represented in this case series had undergone anterior spinal fusion(s). It is possible that posterior fusions might lead to difficulties in lead placements; however, our data cannot directly address this potential limitation.

Our observation of the ability to capture the occipital regions of the head is not surprising. The greater and lesser occipital nerves emanate from the C2 root, and to a lesser extent the C3 root, and connect in the spinal cord within the spinal nucleus of the trigeminal nerve (which becomes the nucleus caudalis in the cervical region) $(39,40)$. Both human and animal studies suggest that this anatomical substrate may be responsible for the sensory convergence observed (41-44). This anatomical and functional overlap may also explain why 1 patient reported paresthesia in the mandible, a sensory region subserved by the trigeminal nerve. Deeper stimulation with increasing pulse widths may eventually stimulate neural structures associated with projections from the greater occipital nerve, thereby producing sensations seeming to be associated with parietal regions. Two patients in this case series noted significant improvement in headaches. This result is similar to those reported by Dario et al who reported treatment of cervicogenic headache via spinal cord stimulation with lead tips placed at the C3 level (12). Also, these results are similar to those observed when utilizing occipital nerve stimulation (45).

Stimulation of more distal structures such as the lower back, legs, and feet can be explained by the anatomical arrangement of sensory fibers within the dorsal columns. As sensory fibers project cephalad from more caudal regions of the body, they assume a more medial position while other sensory fibers from upper extremities course more laterally. Feirabend et al published an elegant anatomical study on the morphometry of the spinal dorsal columns and concluded that lateral fibers demonstrate both an increasing fiber density as well as fiber frequency with a subsequent increase in collateralization (46). This anatomic arrangement would provide a layer of stimulation where weaker electrical fields would stimulate more lateral nerve fibers and other neural structures while stronger electrical fields would be able to recruit more medial fibers and, thus, more caudally located dermatomes. These findings also help explain our observations of a cephalad to caudal paresthesia with increasing current amplitudes or pulse widths. Moreover, stimulation of the cervical spinal cord could effectively manage pain in the lower extremities in conjunction with pain located in the neck and upper extremities.

These observations are in direct contrast to those of Eisenberg and Brecker who reported effective pain management of lower extremity pain (leg and foot pain of cervical origin) with a low thoracic placed spinal cord stimulator (47). These authors reported that, despite the clear cervical origin of the pain, placement of the lead to produce paresthesia in the affected limb could still relieve pain. In contrast, our observations indicate that pain presumably of thoracic or lumbar origin can be effectively treated with cervical lead placement. Thus, it seems that lead placement is less important than the location of the paresthesias that are generated.

In this case series we did not observe any adverse events such as infection or lead migration. Although we did not collect radiographic evidence of anatomical migration, upon reprogramming we could always functionally capture painful regions. Thus, our observations of a lack of lead migration are based upon dermatomal paresthesia mapping and not based upon radiographic imaging. One might anticipate an increased incidence of lead migration in the cervical versus thoracolumbar region due to the relatively greater flexibility and movement in the neck; however, it is not currently known if this is the case. Despite our and others observations of cervical spinal cord stimulation induced headache relief, Ward and Levin reported a case of lead migration causing cervicogenic headache (48). It is hypothesized that stimulation of the trigeminovascular system following migration caused the headaches since repositioning the leads alleviated the headaches. Epidural cervical spinal stimulation also has 
other measurable effects besides analgesia including increasing cerebral blood flow, as well as tumor oxygenation and metabolism (49-53). While interesting, it is unclear what clinical significance this may play.

Despite the often referenced classic publication by Wall and Melzack in 1965 (54) there still exists a very limited amount of basic research data on spinal neuromodulation in the treatment of chronically painful conditions $(11,55)$. Significantly more research needs to be conducted in order to determine the precise mechanisms of action underlying the analgesic effects of spinal cord stimulation. In particular, it would be helpful to know which spinal and super-spinal regions are activated when leads are placed in the neck region versus thoracic regions. Moreover, it will be interesting to see if mechanisms of pain reduction differ between cervical and thoracic lead placement.

In conclusion, our case series suggests that spinal cord stimulation can be an effective treatment for patients with persistent axial neck pain with or without upper extremity pain following failed cervical fusion surgery. A more rigorous prospective study is warranted to directly determine the long-term efficacy as well as document the rate of complications associated with cervical spinal cord stimulation.

\section{References}

1. Abdi S, Datta S, Lucas LF. Role of epidural steroids in the management of chronic spinal pain: A systematic review of effectiveness and complica tions. Pain Physician 2005;8:127-143.

2. Boswell MV, Shah RV, Everett CR, Sehgal N, Brown AM, Abdi S, Bowman RC, 2nd, Deer TR, Datta S, Colson JD, Spillane WF, Smith HS, Lucas LF, Burton AW, Chopra P, Staats PS, Wasserman RA, Manchikanti L. Interventional techniques in the management of chronic spinal pain: Evidence-based practice guidelines. Pain Physician 2005;8:147.

3. Bennett G, Serafini M, Burchiel K, Buchser E, Classen A, Deer T, Du Pen S, Ferrante FM, Hassenbusch SJ, Lou L, Maeyaert J, Penn R, Portenoy RK, Rauck R, Willis KD, Yaksh T. Evidence-based review of the literature on intrathecal delivery of pain medication. J Pain Symptom Manage 2000;20:S12-36.

4. Cameron T. Safety and efficacy of spinal cord stimulation for the treatment of chronic pain: A 20-year literature review. J Neurosurg 2004;100(3 Suppl Spine):254-267.

5. Stojanovic MP, Abdi S. Spinal cord stimulation. Pain Physician 2002;5:156166.

6. Taylor RS, Van Buyten JP, Buchser E. Spinal cord stimulation for complex regional pain syndrome: A systematic review of the clinical and cost-effectiveness literature and assessment of prognostic factors. Eur J Pain 2006;10:91101.
7. Ubbink DT, Vermeulen H. Spinal cord stimulation for non-reconstructable chronic critical leg ischaemia. Cochrane Database Syst Rev 2005:CD004001.

8. Turner JA, Loeser JD, Deyo RA, Sanders SB. Spinal cord stimulation for patients with failed back surgery syndrome or complex regional pain syndrome: $A$ systematic review of effectiveness and complications. Pain 2004;108:137-147.

9. Taylor RS, Taylor RJ, Van Buyten JP, Buchser E, North R, Bayliss S. The cost effectiveness of spinal cord stimulation in the treatment of pain: A systematic review of the literature. J Pain Symptom Manage 2004;27:370-378.

10. Mekhail NA, Aeschbach A, StantonHicks M. Cost benefit analysis of neurostimulation for chronic pain. Clin J Pain 2004; 20:462-468.

11. Linderoth B, Foreman RD. Mechanisms of spinal cord stimulation in painful syndromes: Role of animal models. Pain Med 2006;7 Suppl 1:S14-26.

12. Dario A, Scamoni C, Peron S, Tomei G. A case of post-traumatic cervicogenic headache treated by cervical cord stimulation. J Headache Pain 2005;6:473.

13. V an Buyten JP. Neurostimulation for chronic neuropathic back pain in failed back surgery syndrome. I Pain Symptom Manage 2006;31(4 Suppl):S25-29.

14. North RB, Kidd DH, Petrucci L, Dorsi MJ. Spinal cord stimulation electrode design: A prospective, randomized, controlled trial comparing percutaneous with laminectomy electrodes: Part ii-clinical outcomes. Neurosurgery
2005;57:990-996; discussion 990-996.

15. North RB, Kidd DH, Olin J, Sieracki JM, Farrokhi F, Petrucci L, Cutchis PN. Spinal cord stimulation for axial low back pain: A prospective, controlled trial comparing dual with single percutaneous electrodes. Spine 2005;30:14121418.

16. Wetzel FT, Hassenbusch SJ, Oakley JC, Willis KD, Simpson RK, Ross EL. Treatment of chronic pain in failed back surgery patients with spinal cord stimulation: A review of current literature and proposal for future investigation. Neuromodulation 2000;3:59-74.

17. North RB, Guarino AH. Spinal cord stimulation for failed back surgery syndrome: Technical advances, patient selection and outcome. Neuromodulation 1999;2:171-178.

18. Guyer RD, Patterson M, Ohnmeiss DD. Failed back surgery syndrome: Diagnostic evaluation. J Am Acad Orthop Surg 2006;1:534-543.

19. North RB, Kidd DH, Farrokhi F, Piantadosi SA. Spinal cord stimulation versus repeated lumbosacral spine surgery for chronic pain: A randomized, controlled trial. Neurosurgery 2005;56:98-106; discussion 106-107.

20. Daousi C, Benbow SJ, MacFarlane IA. Electrical spinal cord stimulation in the long-term treatment of chronic painful diabetic neuropathy. Diabet Med 2005;22:393-398.

21. Tesfaye S, Watt J, Benbow SJ, Pang KA, Miles J, MacFarlane IA. Electrical spinal-cord stimulation for painful diabet- 
ic peripheral neuropathy. Lancet 1996; 348:1698-1701.

22. Kumar K, Toth C, Nath RK. Spinal cord stimulation for chronic pain in peripheral neuropathy. Surg Neurol 1996;46:363-369.

23. Bennett DS, Brookoff D. Complex regional pain syndromes (reflex sympathetic dystrophy and causalgia) and spinal cord stimulation. Pain Med 2006;7 Suppl 1:S64-96.

24. Taylor RS. Spinal cord stimulation in complex regional pain syndrome and refractory neuropathic back and leg pain/failed back surgery syndrome: Results of a systematic review and meta-analysis. I Pain Symptom Manage 2006;31(4 Suppl):S13-19.

25. Sibell DM, Colantonio AJ, Stacey BR. Successful use of spinal cord stimulation in the treatment of severe raynaud's disease of the hands. Anesthesiology 2005;102:225-227.

26. Neuhauser B, Perkmann R, Klingler PJ, Giacomuzzi S, Kofler A, Fraedrich G. Clinical and objective data on spinal cord stimulation for the treatment of severe raynaud's phenomenon. $A m$ Surg 2001;67:1096-1097.

27. Robaina FJ, Dominguez M, Diaz M, Rodriguez JL, de Vera JA. Spinal cord stimulation for relief of chronic pain in vasospastic disorders of the upper limbs. Neurosurgery 1989;24:63-67.

28. Vallejo R, Fidalgo-Perez I, Canceller Malo JM, Marin Paredes M, Kramer J. Spinal Neuromodulation: A novel approach in the management of peripheral vascular disease. Techniques in Regional Anesthesia and Pain Management 2006;10:3-6.

29. Erdek MA, Staats PS. Spinal cord stimulation for angina pectoris and peripheral vascular disease. Anesthesiol Clin North America 2003;21:797-804.

30. Augustinsson LE. Spinal cord stimulation in peripheral vascular disease and angina pectoris. J Neurosurg Sci 2003;47(1 Suppl :37-40.

31. Tallis R, Jacobs M, Miles J. Spinal cord stimulation in peripheral vascular disease. Br J Neurosurg 1992;6:101-105.

32. Piva B, Shaladi A, Saltari R, Gilli G. Spinal cord stimulation in the management of pain from brachial plexus avulsion. Neuromodulation 2003;6:27-31.

33. Kumar K, Toth C, Nath RK, Laing P. Epidural spinal cord stimulation for treat- ment of chronic pain-some predictors of success. A 15-year experience. Surg Neurol 1998; 50:110-120; discussion 120-111.

34. North RB, Ewend MG, Lawton MT, Kidd DH, Piantadosi S. Failed back surgery syndrome: 5-year follow-up after spinal cord stimulator implantation. Neurosurgery 1991;28:692-699.

35. Kaplan M, Dreyfuss P, Halbrook B, Bogduk N. The ability of lumbar medial branch blocks to anesthetize the zygapophysial joint. A physiologic challenge. Spine 1998;23:1847-1852.

36. Manchikanti L, Singh V, Pampati V. Are diagnostic lumbar medial branch blocks valid? Results of a 2 year followup. Pain Physician 2003;6:147-153.

37. Manchikanti L, Damron K, Cash K, Manchukonda R, Pampati V. Therapeutic cervical medial branch blocks in managing chronic neck pain: A preliminary report of a randomized, double-blind, controlled trial: Clinical trial NCTo033272. Pain Physician 2006;9:333-346.

38. Boswell MV. Therapeutic cervical medial branch blocks: A changing paradigm in interventional pain management. Pain Physician 2006;9:279-281.

39. Taren JA, Kahn EA. Anatomic pathways related to pain in face and neck. J Neurosurg 1962;19:116-121.

40. Bernard EJ, Jr., Nashold BS, Jr., Caputi F, Moossy JJ. Nucleus caudalis drez lesions for facial pain. $\mathrm{Br} /$ Neurosurg 1987;1:81-91.

41. usch V, Jakob W, Juergens T, SchulteMattler W, Kaube H, May A. Functional connectivity between trigeminal and occipital nerves revealed by occipital nerve blockade and nociceptive blink reflexes. Cephalalgia 2006;26:50-55.

42. Piovesan EJ, Kowacs PA, Oshinsky ML. Convergence of cervical and trigeminal sensory afferents. Curr Pain Headache Rep 2003;7:377-383.

43. Goadsby PJ, Knight YE, Hoskin KL. Stimulation of the greater occipital nerve increases metabolic activity in the trigeminal nucleus caudalis and cervical dorsal horn of the cat. Pain 1997;73:23-28.

44. Bogduk N. Headaches and the cervical spine. Cephalalgia 1984;4(1):7-8.

45. Vallejo R, Benyamin R, Kramer J. Neuromodulation of the occipital nerve in pain management. Techniques in $\mathrm{Re}$ - gional Anesthesia and Pain Management 2006;10:12-15.

46. Feirabend HK, Choufoer H, Ploeger S, Holsheimer J, van Gool JD. Morphometry of human superficial dorsal and dorsolateral column fibres: Significance to spinal cord stimulation. Brain 2002;125 (Pt 5):1137-1149.

47. Eisenberg E, Brecker C. Lumbar spinal cord stimulation for cervical-originated central pain: A case report. Pain 2002;100:299-301.

48. Ward TN, Levin M. Case reports: Headache caused by a spinal cord stimulator in the upper cervical spine. Headache 2000;40:689-691.

49. Robaina F, Clavo B, Catala L, Carames MA, Morera J. Blood flow increase by cervical spinal cord stimulation in middle cerebral and common carotid arteries. Neuromodulation 2004;7:26-31.

50. Clavo B, Robaina F, Montz R, Domper M, Carames MA, Morera J, Pinar B, Hernandez MA, Santullano V, Carreras JL. Modification of glucose metabolism in brain tumors by using cervical spinal cord stimulation. J Neurosurg 2006;104:537-541.

51. Clavo B, Robaina F, Catala L, Perez JL, Lloret M, Carames MA, Morera J, Lopez L, Suarez G, Macias D, Rivero J, Hernandez MA. Effect of cervical spinal cord stimulation on regional blood flow and oxygenation in advanced head and neck tumours. Ann Oncol 2004;15:802807.

52. Clavo B, Robaina F, Catala L, Valcarcel B, Morera J, Carames MA, Ruiz-Egea E, Panero F, Lloret M, Hernandez MA. Increased locoregional blood flow in brain tumors after cervical spinal cord stimulation. J Neurosurg 2003;98:12631270.

53. Clavo B, Robaina F, Morera J, Ruiz-Egea E, Perez JL, Macias D, Carames MA, Catala L, Hernandez MA, Gunderoth M. Increase of brain tumor oxygenation during cervical spinal cord stimulation. Report of three cases. I Neurosurg 2002;96(1 Suppl):94-100.

54. Melzack R, Wall PD. Pain mechanisms: A new theory. Science 1965;150:971979.

55. Linderoth B, Foreman RD. Physiology of spinal cord stimulation: Review and update. Neuromodulation 1999;2:150164 . 
